\title{
Transfusion requirements in patients with gastrointestinal bleeding: a study in a Blood Unit at a referral hospital
}

\author{
A. Garrido, J. L. Márquez, F. J. Guerrero', M. A. Pizarro, E. Leo and A. Giráldez \\ Gatrointestinal Bleeding Unit. Hospital Virgen del Rocío. Seville. ${ }^{1}$ Department of Internal Medicine. Hospital Virgen \\ Macarena. Seville, Spain
}

\begin{abstract}
Objectives: 1 . To study transfusion requirements in the Department of Gastroenterology of a Tertiary Referral Hospital, and their evolution over the last seven years. 2. To analyze risk factors associated with greater erythrocyte transfusion requirements.

Patients and methods: erythrocyte transfusion requirements were compared for patients admitted to the Department of Gastroenterology at Hospital Virgen del Rocío, Seville, from 1999 to 2005. Clinical data of interest have been analyzed in order to determine factors associated with greater transfusion requirements.

Results: 1,611 patients with a mean age of 60.45 years (59.7-61.2) were included in this study; $76.41 \%$ were males. Gastric ulcers were the cause of bleeding in $18.4 \%$ of cases (with $69 \%$ requiring transfusions); duodenal ulcers caused $22.2 \%$ of cases (with 52.9\% requiring transfusions), and portal hypertension caused $33.6 \%$ of cases (with $90.2 \%$ requiring transfusions).

Upper and lower gastrointestinal bleeding of unknown origin requires transfusions in 88.9 and $96.2 \%$ of cases, respectively.

A multivariate logistic regression analysis showed that clinical presentations such as hematemesis (odds ratio $=3.12$ ), hematochezia (odds ratio $=33.17$ ), gastrointestinal hemorrhage of unknown origin (odds ratio $=6.57$ ), and hemorrhage as a result of portal hypertension (odds ratio $=3.43$ ) were associated with greater transfusion requirements for erythrocyte concentrates.

No significant differences were observed between the percentages of patients who received transfusions from 1999 to 2005.

Conclusions: 1 . No differences have been observed between the percentages of patients who received transfusions over the last seven years at our Department of Gastroenterology. 2. Patients presenting with hematemesis or hematochezia, in addition to those with bleeding of unknown origin or from portal hypertension, are prone to have greater transfusion requirements.
\end{abstract}

Key words: Gastrointestinal bleeding. Packed erythrocyte transfusion. Department of Gastroenterology.

Recibido: 17-04-06.

Aceptado: 28-06-06.

Correspondencia: Antonio Garrido Serrano. C/ Carmen de Burgos, 19. Hacienda La Cartuja. 41940 Tomares. Sevilla. e-mail: agarridos@interec.org
Garrido A, Márquez JL, Guerrero FJ, Pizarro MA, Leo E, Giráldez A. Transfusion requirements in patients with gastrointestinal bleeding: a study in a Blood Unit at a referral hospital. Rev Esp Enferm Dig 2006; 98: 760-769.

\section{INTRODUCTION}

Gastrointestinal bleeding is a significant cause of morbidity and mortality, and takes up a considerable amount of health resources (1), including the transfusion of blood components and more specifically packed erythrocytes. A secondary demand is increasingly becoming a more complex type of care, and the number of patients is also increasing, factors which require a more rigorous management of blood banks. Given the frequent shortage of these products, this factor is even more important.

Packed erythrocyte transfusion is a transitory measure, since the deficiency regresses unless the cause is treated; furthermore, treatment must be individualized depending on factors such as age, symptoms, hemodynamic situation, and concomitant illnesses (2). As a result, transfusions in patients with severe gastrointestinal bleeding must be evaluated in a risk/benefit context, without the current tendencies pointing at a specific value of hematocrit from which to indicate packed erythrocyte transfusion (3). Furthermore, the fact that actual hemoglobin values decrease within 24-48 hours due to a dilution effect must always be taken into account.

Transfusion support is a basic element in the treatment of acute, persisting gastrointestinal bleeding, which may present a high mortality rate ranging from 5 to $10 \%$ according to the various series $(1,4)$, and therefore its use is a routine in Departments of Gastroenterology in which such patients are treated. 
In this study we will evaluate the transfusion requirements of a Blood Unit in a tertiary referral hospital and their evolution over the last seven years. We will also examine the factors associated to a greater need for packed erythrocyte transfusion.

\section{PATIENTS AND METHODS}

A retrospective study covering the period 1999-2005 was carried out in all patients admitted both for upper and lower gastrointestinal bleeding with hemodynamic instability or risk of hemorrhage persistence/recurrence in the Blood Unit at "Hospital Virgen del Rocio", Seville (a tertiary referral hospital offering medical assistance to a population of 735,973 inhabitants, and with a Gastroenterology Consultant on duty to carry out early or urgent endoscopy procedures as needed).

In all cases registration details were taken, including sex and age upon admittance; personal history of tobacco and alcohol use (tobacco use being considered the smoking of more than 10 cigarettes/day, and alcohol use the regular consumption of more than $80 \mathrm{~g}$ of alcohol/day for males and $40 \mathrm{~g} /$ day for females). A history of aspirin or other non-steroidal anti-inflammatory drugs use -in addition to other oral anticoagulants or platelet inhibitorswas considered when clearly reflected in the clinical history by the patient or their family members.

With regard to type of hemorrhage, this was classified as: upper gastrointestinal bleeding (originating between the upper esophageal sphincter and Treitz's angle) or lower gastrointestinal bleeding (from Treitz's angle to the anal margin). We also evaluated the form of clinical presentation of the hemorrhage, including hematemesis, melenas, haematochezia or rectorrhagia, in addition to the hemodynamic situation of the patient, which was defined as stable when the following criteria were fulfilled: systolic arterial pressure higher than $100 \mathrm{mmHg}$, heart rate lower than 100 beats/minute, no changes to arterial pressure and heart rate following orthostatism, no clinical signs of peripheral hypoperfusion, and diuresis exceeding $30 \mathrm{ml} / \mathrm{h}$; and as hemodynamic instability when two or more of the following criteria were fulfilled: systolic arterial pressure lower than $100 \mathrm{mmHg}$, heart rate higher than 100 beats/minute, clinical signs of peripheral hypoperfusion, and significant changes in arterial pressure and heart rate following orthostatism.

The etiology of upper gastrointestinal bleeding was recorded as follows: duodenal ulcer, gastric ulcer, Mallory-Weiss, hemorrhage from portal hypertension (PHT), upper gastrointestinal bleeding (UGIB) of unknown origin, etc.; lower gastrointestinal bleeding was classified according to its etiology as follows: diverticular disease, angiodysplasia, lower gastrointestinal bleeding (LGIB) of unknown origin, and other. Furthermore, all cases in which some type of therapeutic endoscopy was carried out (injection of substances, electrocoagulation, treatment with argon plasma, etc.) were recorded.

The evolution of patients was classified as: a) favorable: in cases where there was no evidence of new episodes of external hemorrhage, the hemodynamic situation was maintained stable, and there were no decreases in hematocrit; b) hemorrhagic recurrence: within 48 hours if the need for fluid perfusion exceeded $1,000 \mathrm{ml} / \mathrm{h}$ in order to maintain hemodynamic stability, or if there was a decrease of at least 7 points of hematocrit accompanied by "fresh melena", or new episodes of hematemesis or rectorrhagia. From the third day on it was considered recurrent when new episodes of external hemorrhage occurred. In the event of hemorrhagic recurrence the cases in which there was a second endoscopic therapy were recorded; c) need for surgical treatment; and d) patient recovery.

The total number of days in which the patient remained in the Blood Unit were counted, in addition to the total number of packed erythrocytes used for transfusion during the patient's stay. The decision to give a transfusion was individualized for each patient; however, in general, it was considered in patients with no concomitant pathologies when the hematocrit value was below $24 \%$ or hemoglobin values were below 7-8 g/dl.

Statistical study: several quantitative and qualitative variables were included, expressed as an average or percentage respectively, with $95 \%$ confidence intervals. In the logistic regression analysis (Tables II and III), variable predictors of clinical interest were included, considering blood transfusion (yes/no) as a dependent variable. The ANOVA test 1 factor was carried out (Tables IV and $\mathrm{V})$ in order to compare transfusion requirements according to the different years in the study and the various etiologies of gastrointestinal hemorrhage, respectively. Statistical significance was declared for $p<0.05$. The statistical analysis was carried out with the SPSS 12 software program.

\section{RESULTS}

During the period 1999-2005, 1,611 patients admitted to the Blood Unit, Department of Gastroenterology, "Hospital Virgen del Rocío", Seville, Spain, were included in this study $-76.41 \%$ were males (74.3-78.5) and $23.59 \%$ were females (21.4-25.8), with a mean age of $60.45 \pm 15.59$ years (59.7-61.2). A total of 4,027 packed erythrocyte transfusions were given over this period, with an average of 2.4 (1.9-2.8) per patient.

Table I shows the general characteristics of all patients in the sample with regard to their history, form of presentation, and etiologic diagnosis; it should be pointed out that $36.70 \%$ were patients with a history of alcohol use and $34.5 \%$ had a prior treatment with non-steroidal antiinflammatory drugs; gastroduodenal ulcers were the cause of $40.60 \%$ of hospital admissions $(18.40 \%$ were 
Table I. Sample general characteristics $(n=1,611)$

\begin{tabular}{lcc}
\hline Variables & Mean & $95 \% \mathrm{Cl}$ \\
\hline A. General information & & \\
Age (years) & 60.45 & $59.7-61.2$ \\
Males (\%) & 76.41 & $74.3-78.5$ \\
Tobacco use (\%) & 26.70 & $24.6-28.9$ \\
Alcohol use (\%) & 36.70 & $34.3-39.1$ \\
Prior treatment with NSAIDs (\%) & 34.5 & $32.6-37.3$ \\
Treated with anticoagulants (\%) & 7.1 & $6.0-8.6$ \\
& & \\
B. Clinical presentation of hemorrhage & & \\
Hematemesis (\%) & 50.22 & $47.8-52.7$ \\
Melenas (\%) & 53.88 & $51.4-56.3$ \\
Rectorrhagia (\%) & 13.70 & $12.0-15.5$ \\
Hematochezia (\%) & 2.60 & $1.9-3.5$ \\
& & \\
C. Etiologic diagnosis & & \\
Gastric ulcer (\%) & 18.40 & $16.6-20.4$ \\
Duodenal ulcer (\%) & 22.20 & $20.2-24.3$ \\
Mallory-Weiss (\%) & 5.00 & $4.0-6.30$ \\
Angiodysplasia (\%) & 1.60 & $1.0-2.30$ \\
Portal hypertension (\%) & 33.60 & $31.3-36.0$ \\
Diverticulosis (\%) & 3.60 & $2.8-4.70$ \\
UGIB of unknown origin (\%) & 1.70 & $1.1-2.20$ \\
LGIB of unknown origin (\%) & 3.30 & $2.5-4.30$ \\
Other (\%) & 10.70 & $9.4-12.5$ \\
\hline T. & & \\
\hline
\end{tabular}

T: treatment; NSAIDs: non-steroidal anti-inflammatory drugs. UGIB: upper gastrointestinal bleeding. LGIB: lower gastrointestinal bleeding.

gastric ulcers and $22.20 \%$ were duodenal ulcers), and hemorrhage from portal hypertension was the cause in $33.60 \%$ of cases. Therefore, both etiologies together make up three quarters of admissions to the Blood Unit.

Table II shows that the presentation of the hemorrhagic episode as hematochezia was associated to a greater transfusion risk and higher transfusion requirements (odds ratio $=33.17$ ), followed by hematemesis (odds ratio $=3.12$ ).

With regard to transfusion requirements in accordance with the etiology of hemorrhage $69 \%$ of patients with gastric ulcer required transfusions (63.4-74.2), as did $52.9 \%$ with duodenal ulcer $(47.6-58.2), 90.2 \%$ with portal hypertension (87.3-95.2), 88.9\% with upper gastroin-

Table II. Link between the presentation forms of gastrointestinal bleeding and transfusion risk. Multivariate logistic regression analysis $(n=1,611)$

\begin{tabular}{lccc}
\hline Variables & Odds ratio & $95 \% \mathrm{Cl}$ & $p$ \\
\hline Age & 1.01 & $1.01-1.02$ & $<0.001$ \\
Sex (male/female) & 0.67 & $0.50-0.90$ & $<0.001$ \\
Hematemesis & 3.12 & $2.21-4.22$ & $<0.001$ \\
Melenas & 1.59 & $1.10-2.29$ & $<0.014$ \\
Hematochezia & 33.17 & $4.48-250$ & $<0.001$ \\
Rectorrhagia & 1.39 & $0.84-2.31$ & NS \\
\hline
\end{tabular}

Corrected with consumption of alcohol and tobacco, prior treatment with anticoagulants, and non-steroidal anti-inflammatory drugs. testinal bleeding of unknown origin (69.7-97.1), and $96.2 \%$ with lower gastrointestinal bleeding of unknown origin (85.9-99.3). The multivariate logistic regression analysis of these results in table III confirmed that indeed gastrointestinal bleeding of unknown origin and hemorrhage from portal hypertension are independently associated with greater transfusion requirements.

Table III. Link between the etiological diagnosis of gastrointestinal bleeding and transfusion risk. Multivariate logistic regression analysis $(n=1,611)$

\begin{tabular}{lccc}
\hline Variables & Odds ratio & $95 \% \mathrm{Cl}$ & $p$ \\
\hline Age & 1.01 & $1.00-1.02$ & $<0.05$ \\
Sex (male/female) & 0.70 & $0.51-0.95$ & $<0.03$ \\
Gastric ulcer & 0.65 & $0.25-1.70$ & $\mathrm{NS}$ \\
Duodenal ulcer & 0.34 & $0.13-0.89$ & $\mathrm{NS}$ \\
Portal hypertension & 3.43 & $1.30-9.08$ & $<0.02$ \\
Diverticulosis & 0.30 & $0.11-0.86$ & $<0.03$ \\
Angiodysplasia & 0.65 & $0.18-2.33$ & $\mathrm{NS}$ \\
UGIB of unknown origin & 2.40 & $0.52-11.01$ & $<0.02$ \\
LGIB of unknown origin & 6.57 & $1.22-35.42$ & $<0.01$ \\
Mallory-Weiss & 0.34 & $0.12-0.096$ & $\mathrm{NS}$ \\
Other & 0.24 & $0.09-0.62$ & $<0.04$
\end{tabular}

Corrected with consumption of alcohol and tobacco, prior treatment with anticoagulants, and non-steroidal anti-inflammatory drugs.

Table IV shows the average packed erythrocytes per patient throughout the study period, in addition to the percentage of patients who required a transfusion, observing no significant differences throughout the period 1999-2005. No differences were observed throughout the period 1999-2005 in the percentage of patients undergoing anticoagulation therapy who required transfusions, with their respective figures as follows: $8.3 \%$ (5-13.4),

\begin{tabular}{lcccc}
\multicolumn{5}{c}{$\begin{array}{c}\text { Table IV. Average amount of packed erythrocytes per } \\
\text { patient/year and percentage of patients who received } \\
\text { transfusions each year }\end{array}$} \\
\hline Year & $\begin{array}{c}\text { Erythrocyte cells } \\
\text { (average + 95\% Cl) }\end{array}$ & $\begin{array}{c}\text { Patients who received } \\
\text { transfusions } \\
\text { (percentage + 95\% Cl) }\end{array}$ & & \\
\hline 1999 & $2.2(1.9-2.4)$ & $69.4(62.3-75.7)$ & & \\
2000 & $2.5(2.2-2.8)$ & $71.4(64.6-77.3)$ & & \\
2001 & $2.3(2-2.5)$ & $71(64.1-77.1)$ & & \\
2002 & $2.2(1.9-2.4)$ & $68.4(61.9-74.4)$ & 1,093 & ns \\
2003 & $2.5(2.2-2.8)$ & $70.5(64.4-75.9)$ & & \\
2004 & $2.6(2.3-2.8)$ & $70.8(64.8-76.1)$ & & \\
2005 & $2.5(2.2-2.8)$ & $67.4(61.4-72.9)$ & & \\
\hline
\end{tabular}

F: test of homogeneity of variance in a single factor ANOVA test. 
Table V. Transfusion requirements (packed erythrocyte bags) in descending order for the various etiological forms of gastrointestinal bleeding $(n=1,121)$

\begin{tabular}{lcccc}
\hline Variables & Mean & $95 \% \mathrm{Cl}$ & $F$ & $p$ \\
\hline UGIB of unknown origin & 5.50 & $3.7-7.3$ & & \\
LGIB of unknown origin & 4.56 & $3.9-5.3$ & & \\
Portal hypertension & 3.99 & $3.8-4.2$ & & \\
Gastric ulcer & 2.85 & $2.7-3.0$ & & \\
Diverticulosis & 2.84 & $2.2-3.5$ & 23.87 & $<0.001$ \\
Other & 2.71 & $2.4-3.0$ & & \\
Mallory-Weiss & 2.66 & $2.4-2.9$ & & \\
Duodenal ulcer & 2.63 & $2.4-2.8$ & & \\
Angiodysplasia & 2.58 & $2.1-3.0$ & & \\
\hline
\end{tabular}

F: test of homogeneity of variance in a single factor ANOVA test; UGIB: upper gastrointestinal bleeding; LGIB: lower gastrointestinal bleeding

$7.9 \%(6.2-11.5), 8 \%(4.8-12.9), 6.2 \%(3.6-10.4), 7.5 \%$ (4.7-11.6), 7.3\% (4.6-11.4), 9.2\% (6.1-13.4), p = ns.

Finally, Table V sorts patients according to their requirements of packed erythrocytes, and it was again confirmed that hemorrhage of unknown origin and those caused by portal hypertension required a greater number of bags when compared to other etiologies.

\section{DISCUSSION}

Gastrointestinal bleeding is a pathology that has a significant impact on medical care services and expenditure. One of the main aims when treating patients with upper or lower gastrointestinal bleeding is to treat hypovolemia resulting from loss of blood. In all cases of gastrointestinal bleeding some form of anemia occurs (to a lesser or greater extent), which may require packed erythrocyte transfusion in order to increase the capacity to transport oxygen (5), but not as a replacement of plasma volume (crystalloid and colloid systems are used in these cases). There is extensive controversy with regard to the establishment of a transfusion threshold, especially when it has been shown that transfusion is a risk factor for shock in case of poor patient outcome from adverse immunological consequences (6).

Consequently, while studies carried out on humans recommended maintaining hemoglobin over $10 \mathrm{~g} / \mathrm{dl}$ for resuscitation following hemorrhagic shock (7), the American Society of Anesthesiologists (8) now recommends a value of hemoglobin exceeding $6 \mathrm{~g} / \mathrm{dl}$, while the EU Health Institute (9) recommends a value exceeding $7 \mathrm{~g} / \mathrm{dl}$.

Therefore, it can be concluded that a patient would never receive a transfusion in cases where hemoglobin exceeds $10 \mathrm{~g} / \mathrm{dl}$, and then transfusion would occur in all cases with hemoglobin below $6 \mathrm{~g} / \mathrm{dl}$. We would establish a threshold value for hemoglobin ranging between $7-8 \mathrm{~g} / \mathrm{dl}$, depending on the characteristics of each specific case (speed of blood loss, state of cardiovascular reserve, pathology in another organ or vital system, injury causing the bleeding, etc.).

In our broad series of patients, the clinical presentation of hemorrhage as hematochezia or hematemesis was linked to greater transfusion requirements. This was due to the fact that these are linked to a larger volume of blood loss with hemodynamic repercussion, and thus the presence of isolated melenas is a predictive sign of massive hemorrhage in $5-10 \%$ of cases, compared to $21 \%$ of patients with red hematemesis and 30\% with hematochezia $(10,11)$. Therefore, considering the basic information of the form of clinical presentation regarding hemorrhage included in the patient's medical record we can initially classify the patient as having mild or serious hemorrhage, and take the required measures in each case (emergency endoscopy, blood volume replacement, reserve and transfusion of packed erythrocytes, etc.).

In the majority of patients with gastrointestinal bleeding the origin of the bleeding is identified using conventional diagnostic tests (gastroscopy and colonoscopy). Nevertheless, in $5 \%$ of cases, as in our study, bleeding persisted without being diagnosed by these methods, what is known as gastrointestinal bleeding of unknown origin $(12,13)$. However, if an isolated study does not find differences with regard to number of days that a patient is hospitalized, transfusion requirements, need for surgery, and prognosis compared to other causes of hemorrhage (14), the majority of authors agree that the management and treatment of these diseases is usually problematic and takes up a significant quantity of healthcare resources, including multiple transfusions and cases where patients need admission $(12,13)$. This was reflected in our study, in which the entity was associated to a greater need for transfusion. The explanation for this may be due to the fact that most injuries leading to gastrointestinal bleeding of unknown origin are located in the small intestine (13), an area that cannot be reached by conventional endoscopy; in other pathologies, endoscopic treatment has been shown to decrease the volume of persistent and recurring hemorrhage, and therefore transfusion requirements (15); it requires tests for its diagnosis, including arteriography, videocapsule, or radiological examinations of the small intestine.

Double-balloon enteroscopy is a new technique described by Yamamoto et al. (16) that facilitates the study of the complete small intestine, simultaneously diagnosing and treating all injuries found. In a recent study including 137 patients in whom a double-balloon enteroscopy was carried out, injuries were found in 109 patients (79\%) and the most frequent findings were arteriovenous malformations, which were treated with plasma argon (17). Therefore, this technique is a useful method that can decrease persistent bleeding in these injuries and -as a result- decrease transfusion requirements, a factor that needs to be demonstrated in future randomized, controlled studies (18). 
Following gastrointestinal bleeding of unknown origin, hemorrhages due to portal hypertension are another significant cause of health resource usage in our area, and therefore of packed erythrocyte transfusion requirements. This results from significant blood losses in these hemorrhage episodes, with hemodynamic repercussions and frequent coagulopathy linked to hepatocellular failure; in fact, even though over the last two decades the survival rate of these patients has substantially improved following an episode of variceal hemorrhage, mortality rates are still high (around 20\%) (19). Current guidelines recommend avoiding overtransfusion and maintaining hemoglobin levels around $8 \mathrm{~g} / \mathrm{dl}$ or a hematocrit of $24 \%$ (20); this is based on experimental studies, which indicate that an excessive blood replacement leads to an increase in portal pressure through a rebound effect, and prevents reflex visceral vasoconstriction, which produces a spontaneous interruption of hemorrhage, thus reducing portal-collateral blood flow and portal pressure (21).

In our area the most frequent etiology of cirrhosis is excessive alcohol use; the World Health Organization places alcohol as the third cause of disability in the Western World (22). For this reason, the early identification of a hazardous drinker (23) can contribute to stopping the progression of hepatic diseases towards cirrhosis, and thus may decrease the risk of hemorrhage from portal hypertension, transmission requirements, admissions, and mortality in these patients (24).

The recombinant active factor VII in patients with gastrointestinal hemorrhage and associated coagulopathy promotes the formation of a fibrin clot in places where there is vascular damage or injury. It also forms a complex with the tissue factor exposed, and acts on activated platelets (25). A study has recently been published on the use of rFVIIa in upper gastrointestinal hemorrhage from esophagogastric varices, with favorable results (26), in addition to hemorrhage from other etiologies (27). Therefore, further studies are required to definitely confirm that the rVIIa factor can play an important role in reducing transfusion requirements and in obtaining adequate hemostasis in patients with acute gastrointestinal bleeding, in addition to studying the cost-benefit ratio, as this treatment involves a very high cost.

With regard to hemorrhage from gastroduodenal ulcer, there is no doubt that $H$. pylori eradication -an adequate prophylaxis to prevent injuries following the ingestion of aspirin or other non-steriodal anti-inflammatory drugshas helped, together with the development of therapeutic endoscopy, to decrease the incidence and number of complications $(28,29)$.

Thus, during the last 7 years and then at present there is still a significant demand for hemoderivatives when treating patients requiring transfusions, and therefore efforts should be directed at preventing these complications and optimizing resources.

\section{REFERENCES}

1. Laine L, Peterson WL. Bleeding peptic ulcer. N Engl J Med 1994; 331: 717-27.

2. Murphy MF, Wallington TB, Kelsey P, Boulton F, Bruce M, Cohen $\mathrm{H}$, et al. Guidelines for the clinical use of red cell transfusions. Br J Haematol 2001; 113: 24-31.

3. Villarejo F, Pizzolo M, López E, Domeniconi G, Arto G, Apezteguia C. Acute anemia in high digestive haemorrhage. Margins of security for their handling without transfusion of red globules. Acta Gastroenterol Latinoam 1999; 29: 279-80.

4. Gilbert DA. Epidemiology of upper gastrointestinal bleeding. Gastrointest Endosc 1990; 36: 8-13.

5. Maltz GS, Siegel JE, Carson JL. Hematologic management of gastrointestinal bleeding. Gastroenterol Clin North Am 2000; 29: 169-87.

6. Malene DL, Dunne J, Tracy JK. Blood transfusion, independent of shock severity, is associated with worse outcome in trauma. J Trauma 2003; 54: 898-905.

7. Czer LSC, Shoemaker WC. Optimal hematocrit value in critically ill postoperative patients. Surg Gyn Obs 1978; 14: 262-7.

8. Practice guidelines for blood component therapy: A report by American Society of Anaesthesiologists Task Force on Blood Component Therapy. Anaesthesiology 1996; 84: 732-47.

9. National Institute of Health Consensus Conference. Perioperative red blood transfusion. JAMA 1988; 260: 2700-3.

10. Wara P, Stodkilde H. Bleeding pattern before admission as guideline for emergency endoscopy. Scand J Gastroenterol 1985; 20: 72-7.

11. Longstreth GF. Epidemiology of hospitalization for acute upper gastrointestinal hemorrhage: A population-based study. Am J Gastroenterol 1995; 90: 206-12.

12. Van Gossum A. Obscure digestive bleeding. Best Pract Res Clin Gastroenterol 2001; 15: 155-74.

13. Zuckerman GR, Prakash C, Askin MP, Lewis BS. AGA technical review on the evaluation and management of occult and obscure gastrointestinal bleeding. Gastroenterology 2000; 118: 201-21.

14. Grunder S, Straumann A, Pirovino M. Gastrointestinal hemorrhage of unknown origin. Schw Med Woch 1998; 128: 846-9.

15. Cook DB, Guyatt GH, Salena BJ, Laine LA. Endoscopic therapy for acute nonvariceal upper gastrointestinal bleeding: A metaanalysis. Gastroenterology 1992; 102: 139-48.

16. Yamamoto H, Sekine Y, Sato Y, Higashizawa T, Miyata T, Lino S, et al. Total enteroscopy with a nonsurgical steerable double-balloon meted. Gastrointest Endosc 2001; 53: 216-20.

17. May A, Nachbar L, Wardak A, Yamamaoto H, Ell C. Double-balloon enteroscopy: Preliminary experience in patients with obscure gastrointestinal bleeding or chronic abdominal pain. Endoscopy 2003; 35: 985-91.

18. Pérez-Cuadrado E, Más P, Hallal H, Shanabo J, Muñoz E, Ortega I, et al. Double-balloon enteroscopy: A descriptive study of 50 explorations. Rev Esp Enferm Dig 2006; 98: 73-8.

19. Bosch J, Abraldes JG, Groszmann R. Current management of portal hypertension. J Hepatol 2003; 38: S54-8.

20. De Franchis R. Evolving Consensus in Portal Hypertension Report of the Baveno IV Consensus Workshop on methodology of diagnosis and therapy in portal hypertension. J Hepatol 2005; 43: 167-76.

21. Castaneda B, Morales J, Lionetti R, Moitinho E, Andreu V, Pérez-delPulgar S, et al. Effects of blood volume restitution following a portal hypertensive-related bleeding in anesthetized cirrhotic rats. Hepatology 2001; 33: 821-5.

22. The World Health Report 2002. Reducing risks, promoting healthy life. Geneve: World Health Organization; 2003.

23. Gual A, Colom J. Identificación temprana del bebedor de riesgo. Med Clin (Barc) 2005; 129: 734-5.

24. Morras M, Mondon S, Ortega L, Gual A. Alcoholismo en el hospital general: mortalidad y hospitalizaciones a los 4 años de su detección. Med Clin (Barc) 2005; 125: 441-7.

25. Hedner U. Novoseven as a universal hemostatic agent. Blood Coagul Fibrinolysis 2000; 11: 107-11.

26. Bosch J, Thabut D, Bendtren F, D’Amico G, Albillos A, González Abraldes J, et al. Recombinant factor VIIa for upper gastrointestinal bleeding in patients with cirrhosis: A randomized double-blind trial. 
Gastroenterology 2004; 127: 1123-30.

27. Lecumberri R, Páramo JA, Hidalgo F, Feliú J, Iglesias R, Rocha E. Reducción de las necesidades transfusionales en hemorragias adquiridas graves mediante factor VII activo recombinante. Med Clin (Barc) 2005; $125: 252-3$

28. Garrido Serrano A, Guerrero Igea FJ, Perianes Hernández C, Arenas
Posadas FJ, Palomo Gil S. Local therapeutic injection in bleeding peptic ulcer: A comparison of adrenaline to adrenaline plus a sclerosing agent. Rev Esp Enferm Dig 2002; 94: 401-5.

29. Miño G, Jaramillo JL, Gálvez C, Carmona C, Reyes A, de la Mata M. Análisis de una serie general prospectiva de 3.270 hemorragias digestivas altas. Rev Esp Enferm Dig 1992; 82: 7-15. 